\title{
Gibbons of the world, dream on
}

\author{
J. Kyle Bohman, MD, ${ }^{a}$ and Gregory J. Schears, $\mathrm{MD}^{\mathrm{b}}$
}

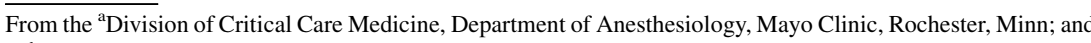 \\ ${ }^{b}$ Division of Pediatric Critical Care Medicine, Department of Anesthesiology, Mayo Clinic, Rochester, Minn. \\ Disclosures: Author have nothing to disclose with regard to commercial support. \\ Received for publication Sept 1, 2015; accepted for publication Sept 2, 2015; available ahead of print Oct 1, 2015 \\ Address for reprints: Gregory J. Schears, MD, Mayo Clinic, 200 First St SW, Rochester, MN 55905 (E-mail: \\ schears.gregory@mayo.edu). \\ J Thorac Cardiovasc Surg 2016;151:13-4 \\ $0022-5223 / \$ 36.00$ \\ Copyright (C) 2016 by The American Association for Thoracic Surgery \\ http://dx.doi.org/10.1016/j.jtcvs.2015.09.005
}

Extracorporeal membrane oxygenation (ECMO) has evolved into an indispensable tool that can reliably support even the most unstable patients with cardiopulmonary failure. Dr John Gibbon's dream was "fulfilled" through the vision and tenacity of Dr Robert Bartlett and other extracorporeal pioneers. ${ }^{1}$ The application of modern ECMO is closer to a contemporary ventricular assist device than ever before, and its success is limited more by our inadequacies of predicting reversibility than by its complications. The recent upsurge in applying this technology must be balanced by the ability of a given center to do what is necessary for these resource-intense patients. Collaboration with experienced ECMO centers is necessary to optimize patient care and avoid paralysis of workflow at smaller institutions. Optimal deployment of ECMO is being threatened by changing financials and publically reported quality measures that could cause recent progress in saving lives to plateau or reverse.

Since its first published successful use in 1972, ECMO technology has advanced tremendously. ${ }^{2}$ What was once a "last resort" high-risk therapy has become a safe, even routine, option deployed at the onset of conventional therapy failure and before significant end-organ damage. ${ }^{3,4}$ In other words, ECMO has become an early rescue strategy rather than a desperate salvage therapy. A simplified and compact ECMO circuit design combined with heparinbonded circuits and growing international experience have accounted for much of the reduction in ECMO-related complications. ${ }^{5,6}$ Meticulous hemostasis, restricted transfusion, and directed collaboration of the care team are essential for improving outcomes. Key areas for exploration and improvement include development of more biocompatible ECMO circuitry, refinement of our understanding, and implementation of anticoagulation and appropriate patient selection. ${ }^{7}$ As an ECMO community, we must identify best practices, standardize protocols, and use more data depth to improve statistical power, study generalizability, and develop more robust selection criterion. ${ }^{8-12}$

For optimal ECMO outcomes, it is essential that patients being considered for ECMO have a reversible cause of

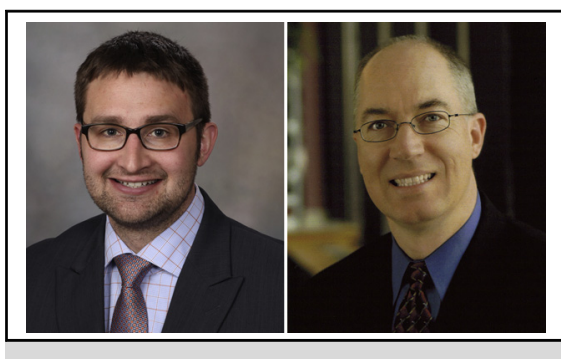

J. Kyle Bohman, MD, and Gregory J. Schears, MD

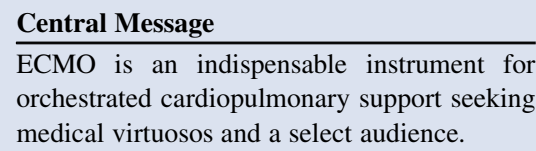

See Articles page 177, 192, 201, 213, 219, 230, and page 1352 in the November issue.

See Editorial Commentaries page 190, 199, 211, 217, 228, and 236.

cardiopulmonary failure or are suitable ventricular assist device or transplant candidates. With the promise of what ECMO can deliver, appropriate patient selection is paramount. In theory, this determination is self-evident, but in practice it is often impossible because of limited data, temporal constraints, and challenging assessment of neurologic status, thus requiring a calculated "leap of faith." The cause of acute cardiopulmonary collapse is often unclear, so it is reasonable to deploy ECMO as a rescue strategy to "buy time" while further diagnostics are being pursued. Clear and digestible communication of this strategy must be brokered with the patient (or patient's surrogate decision maker) so that the ethical dilemma of prolonged ECMO support without a destination therapy can be avoided.

If applied early enough for appropriate patients, ECMO will continue to grow as a reliable method of providing adequate oxygen delivery without the detrimental effects of high-dose vasopressors, and prolonged profound weakness (critical illness myopathy and polyneuropathy) caused by deep sedation and pharmacologic paralysis. Since its early development, ECMO has been used for postcardiotomy cardiogenic shock and acute respiratory distress syndrome. More recently, another growing indication for ECMO has been extracorporeal cardiopulmonary resuscitation (ECPR). ${ }^{13,14}$ Reports from many large ECMO centers 
suggest that if applied quickly enough, ECPR can have a remarkable impact on survival. ${ }^{13,14}$ ECPR is an excellent opportunity for collaboration among cardiothoracic surgeons, emergency department providers, and intensive care providers. A well-orchestrated resuscitation can produce outcomes that defy conventional wisdom.

The Extracorporeal Life Support Organization supports a "spoke and hub" model for ECMO. ${ }^{15,16}$ Tertiary referral centers should collaborate with local medical centers to develop an ECMO network to allow rapid patient access through safe transport, standardized care across institutions, and shared outcome information to further improve the process. These experienced ECMO centers are often more familiar with management of ECMO complications and specialized rehabilitation. ${ }^{17-19}$ Likewise, referral to ECMO-capable centers for very high-risk elective cardiothoracic surgical procedures should be strongly considered preoperatively.

With evolving reimbursement schemes and expansion of hospital (surgeon) performance metrics, one might be hesitant to deploy ECMO for these high-mortality, resource-consuming patients. On an ethical level, clinicians should focus on what is best for the patient. On a practical level, we need to take control of quality metrics pertaining to ECMO to ensure they are accurate, useful, and above all not detrimental to progress. Mortality rates should be calibrated to accurately reflect the severity of disease before admission to one's medical center. We also need to continue to demonstrate the value of ECMO so that it is adequately reimbursed. How we balance increasing healthcare costs with the value of lives saved is a crucial determinate of ECMO's sustainability and further advancement.

ECMO is a powerful tool providing the clinician and patient with options never before possible and whose potential is only beginning to be realized. ECMO must be considered as an integral part of the management of cardiopulmonary instability or collapse, even if the cause is not immediately clear. It has an invaluable ability to support patients who may otherwise be spiraling down the path of multiorgan failure and death. If applied early and with sensible patient selection, it has tremendous potential. As a community, we must develop local ECMO referral networks, combine our data, continue to refine ECMO technology, and remain active in reimbursement and quality measurement policy conversations. ECMO can gift us and our patients additional time for further diagnostics and decision-making while providing adequate end-organ oxygen delivery. Currently, the biggest risks to the success of ECMO are the failure to use it in a timely manner and allowing the system to dictate our decisions. We must fully embrace the spirit of Gibbon and Bartlett and continue to dream on and do.

\section{References}

1. Bartlett RH. John H Gibbon Jr Lecture. Extracorporeal life support: Gibbon fulfilled. J Am Coll Surg. 2014;218:317-27.

2. Hill JD, O’Brien TG, Murray JJ, Dontigny L, Bramson ML, Osborn JJ, et al. Prolonged extracorporeal oxygenation for acute post-traumatic respiratory failure (shock-lung syndrome). Use of the Bramson membrane lung. N Engl J Med. 1972;286:629-34.

3. Rastan AJ, Dege A, Mohr M, Doll N, Falk V, Walther T, et al. Early and late outcomes of 517 consecutive adult patients treated with extracorporeal membrane oxygenation for refractory postcardiotomy cardiogenic shock. J Thorac Cardiovasc Surg. 2010;139:302-11. 311.e1.

4. Papadopoulos N, Marinos S, El-Sayed Ahmad A, Keller H, Meybohm P, Zacharowski K, et al. Risk factors associated with adverse outcome following extracorporeal life support: analysis from 360 consecutive patients. Perfusion. 2015;30:284-90.

5. Brogan TV, Thiagarajan RR, Rycus PT, Bartlett RH, Bratton SL. Extracorporeal membrane oxygenation in adults with severe respiratory failure: a multi-center database. Intensive Care Med. 2009;35:2105-14.

6. Cheng R, Hachamovitch R, Kittleson M, Patel J, Arabia F, Moriguchi J, et al. Complications of extracorporeal membrane oxygenation for treatment of cardiogenic shock and cardiac arrest: a meta-analysis of 1,866 adult patients. Ann Thorac Surg. 2014:97:610-6.

7. Ranucci M. The conundrum of anticoagulation and hemostatic management in ECMO patients. Minerva Anestesiol. June 30, 2015 [Epub ahead of print].

8. Schmidt M, Bailey M, Sheldrake J, Hodgson C, Aubron C, Rycus PT, et al. Predicting survival after extracorporeal membrane oxygenation for severe acute respiratory failure. The Respiratory Extracorporeal Membrane Oxygenation Survival Prediction (RESP) score. Am J Respir Crit Care Med. 2014;189: 1374-82.

9. Schmidt M, Burrell A, Roberts L, Bailey M, Sheldrake J, Rycus PT, et al. Predicting survival after ECMO for refractory cardiogenic shock: the survival after veno-arterial-ECMO (SAVE)-score. Eur Heart J. 2015;36: 2246-56.

10. Schmidt M, Zogheib E, Roze H, Repesse X, Lebreton G, Luyt CE, et al. The PRESERVE mortality risk score and analysis of long-term outcomes after extracorporeal membrane oxygenation for severe acute respiratory distress syndrome. Intensive Care Med. 2013:39:1704-13.

11. Pappalardo F, Pieri M, Greco T, Patroniti N, Pesenti A, Arcadipane A, et al. Predicting mortality risk in patients undergoing venovenous ECMO for ARDS due to influenza A (H1N1) pneumonia: the ECMOnet score. Intensive Care Med. 2013;39:275-81.

12. Peigh G, Cavarocchi N, Keith SW, Hirose H. Simple new risk score model for adult cardiac extracorporeal membrane oxygenation: simple cardiac ECMO score. J Surg Res. 2015;198:273-9.

13. Chen YS, Lin JW, Yu HY, Ko WJ, Jerng JS, Chang WT, et al. Cardiopulmonary resuscitation with assisted extracorporeal life-support versus conventional cardiopulmonary resuscitation in adults with in-hospital cardiac arrest: an observational study and propensity analysis. Lancet. 2008;372:554-61.

14. Morimura N, Sakamoto T, Nagao K, Asai Y, Yokota H, Tahara Y, et al. Extracorporeal cardiopulmonary resuscitation for out-of-hospital cardiac arrest: a review of the Japanese literature. Resuscitation. 2011;82:10-4.

15. Combes A, Brodie D, Bartlett R, Brochard L, Brower R, Conrad S, et al. Position paper for the organization of extracorporeal membrane oxygenation programs for acute respiratory failure in adult patients. Am J Respir Crit Care Med. 2014;190: 488-96.

16. Michaels AJ, Hill JG, Long WB, Young BP, Sperley BP, Shanks TR, et al. Adult refractory hypoxemic acute respiratory distress syndrome treated with extracorporeal membrane oxygenation: the role of a regional referral center. Am J Surg. 2013;205:492-9.

17. Garcia JP, Kon ZN, Evans C, Wu Z, Iacono AT, McCormick B, et al. Ambulatory veno-venous extracorporeal membrane oxygenation: innovation and pitfalls. J Thorac Cardiovasc Surg. 2011;142:755-61.

18. Rehder KJ, Turner DA, Hartwig MG, Williford WL, Bonadonna D, Walczak RJ Jr, et al. Active rehabilitation during extracorporeal membrane oxygenation as a bridge to lung transplantation. Respir Care. 2013;58: $1291-8$.

19. Turner DA, Cheifetz IM, Rehder KJ, Williford WL, Bonadonna D, Banuelos SJ, et al. Active rehabilitation and physical therapy during extracorporeal membrane oxygenation while awaiting lung transplantation: a practical approach. Crit Care Med. 2011:39:2593-8. 